\title{
Management of Soft Tissue Defects of the Ankle and Foot
}

\author{
Lt Col PS Bhandari*, Brig AS Bath, sM $^{+}$, Maj Gen LP Sadhotra, Avsm*, Lt Col Manmohan Singh ${ }^{* *}$, \\ Col MK Mukherjee, YsM $^{++}$
}

\begin{abstract}
Background: Treatment of soft tissue defect of ankle and foot has always been a challenging problem. Methods: Thirty patients with soft tissue defects of the ankle and foot who underwent various reconstructive procedures in two tertiary care teaching hospitals were studied.

Results: Most of the defects $(33 \%)$ were located in and around the ankle. Trauma was the major cause $(56.6 \%)$. Defects were reconstructed with a variety of local, regional, distant and microvascular free flaps. Distally based superficial sural artery flap was used in majority of the cases $(\mathbf{4 0} \%)$. Free tissue transfer using radial artery forearm flap was done in three (10\%) complex wounds where other flaps were not found to be suitable. Superficial soft tissue defects on the dorsum of foot were resurfaced with split thickness skin grafts in $3(\mathbf{1 0} \%)$ cases. Out of 27 flaps used, 26 survived completely. One inferiorly based fasciocutaneous flap developed partial necrosis. There was graft loss in one patient which required regrafting with the stored autograft. Conclusion: Distally based superficial sural artery flap remains the choice for reconstruction of soft tissue defects of ankle and foot because of its reliable blood supply and easy elevation.
\end{abstract}

MJAFI 2005; $61: 253-255$

Key Words: Soft tissue defects; Ankle and foot reconstruction

\section{Introduction}

$\mathrm{C}$ lommon soft tissue problems that afflict the ankle and feet are as a result of trauma, infection, ischaemia and following excisional surgery for tumors. Treatment of these defects is a challenging problem. The difficulty comes from the limited mobility and availability of the overlying skin, the unique weight bearing requirements and the relatively poor circulation of the skin. There are many possible reconstructive options, including local, distant and free flaps. These flaps can be muscle, myocutaneous or fasciocutaneous tissue and each method has its advantages and disadvantages. We present our experience in the management of these defects in 30 patients over a period of 3 years.

\section{Material and Methods}

This study was carried out in two Armed Forces tertiary care teaching hospitals between March 1999 and October 2002. Thirty consecutive patients reporting with soft tissue defects of ankle and foot were included. Patients were examined in detail to exclude underlying medical diseases. Wound swabs were cultured. Underlying bone and tendons were found to be exposed in six and four patients respectively. Trauma due to road traffic accidents accounted for most of the cases. Infection, ischaemia and post excisional soft tissue loss accounted for rest of the cases (Table 1). Most of the defects $(33.3 \%)$ were located in and around the ankle (Table 2). Other sites were dorsum and sole of the foot and posterior heel. Wounds were prepared by excision of the devitalized tissue and freshening of margins. Flaps were then raised and transposed on to the defects. Flap donor sites were grafted with split thickness skin. Three defects with exposed malleoli and tarsal bones were reconstructed with free radial artery forearm flap as local and regional flaps were not available because of scarring or infection. Three superficial soft tissue

Table 1

Causes of soft tissue loss

$\begin{array}{lcc}\text { Causes } & \text { No. of patients } & \text { Percentage } \\ \text { Trauma } & 17 & 56.6 \% \\ \text { Infection } & 6 & 20 \% \\ \text { Ischaemia } & 4 & 13.3 \% \\ \text { Post tumor excision } & 3 & 10 \%\end{array}$

Table 2

Anatomical location of soft tissue defects

$\begin{array}{lcc}\text { Location } & \text { No. of patients } & \text { Percentage } \\ \text { Ankle } & 10 & 33.3 \\ \text { Dorsum of foot } & 8 & 26.6 \\ \text { Sole of foot } & 7 & 23.3 \\ \text { Posterior heel } & 5 & 16.6\end{array}$

"Classified Specialist, ${ }^{++}$Senior Advisor, Surgery and Reconstructive Surgery, ${ }^{\#}$ Commandant, Army Hospital (R\&R) Delhi Cantt, ${ }^{+}$Deputy Commandant, Command Hospital (NC), C/o 56 APO, ${ }^{* *}$ Classified Specialist, Surgery and Reconstructive Surgery, Command Hospital (SC) Pune-40.

Received : 19.01.2003; Accepted : 20.01.2004 
Table 3

\section{Reconstructive procedures}

\section{Procedure}

No. of patients Percentage

I. Pedicle flaps

$\begin{array}{lll}\text { (a) Distally based superficial } & 12 & 40 \\ \text { sural artery flap } & & \\ \text { (b) Instep flap } & 4 & 13.3 \\ \text { (c) Calcaneal artery flap } & 5 & 16.6 \\ \text { (d) Fasciocutaneous flap } & 3 & 10 \\ \text { Free flaps } & 3 & 10 \\ \text { I. Split skin graft } & 3 & 10\end{array}$

defects were resurfaced with split skin grafts. Time between trauma and flap cover varied from 3 hours to 26 days.

\section{Results}

The patients ranged in age from 9 to 72 years (average 58.2). Males outnumbered females in the ratio of $4: 1$. Twenty seven defects were reconstructed with a variety of flaps (Table 3 ). In most cases (12) distally based superficial sural artery flap was used to reconstruct the defect (Figs. 1\&2). 4 instep flaps were used to provide sensory flap cover in the weight bearing heel. Posterior heel defects were reconstructed with calcaneal artery flap (5). Inferiorly based fasciocutanenous flaps were used in 3 cases. Free tissue transfer with radial artery forearm flap was done in 3 cases as other flaps were

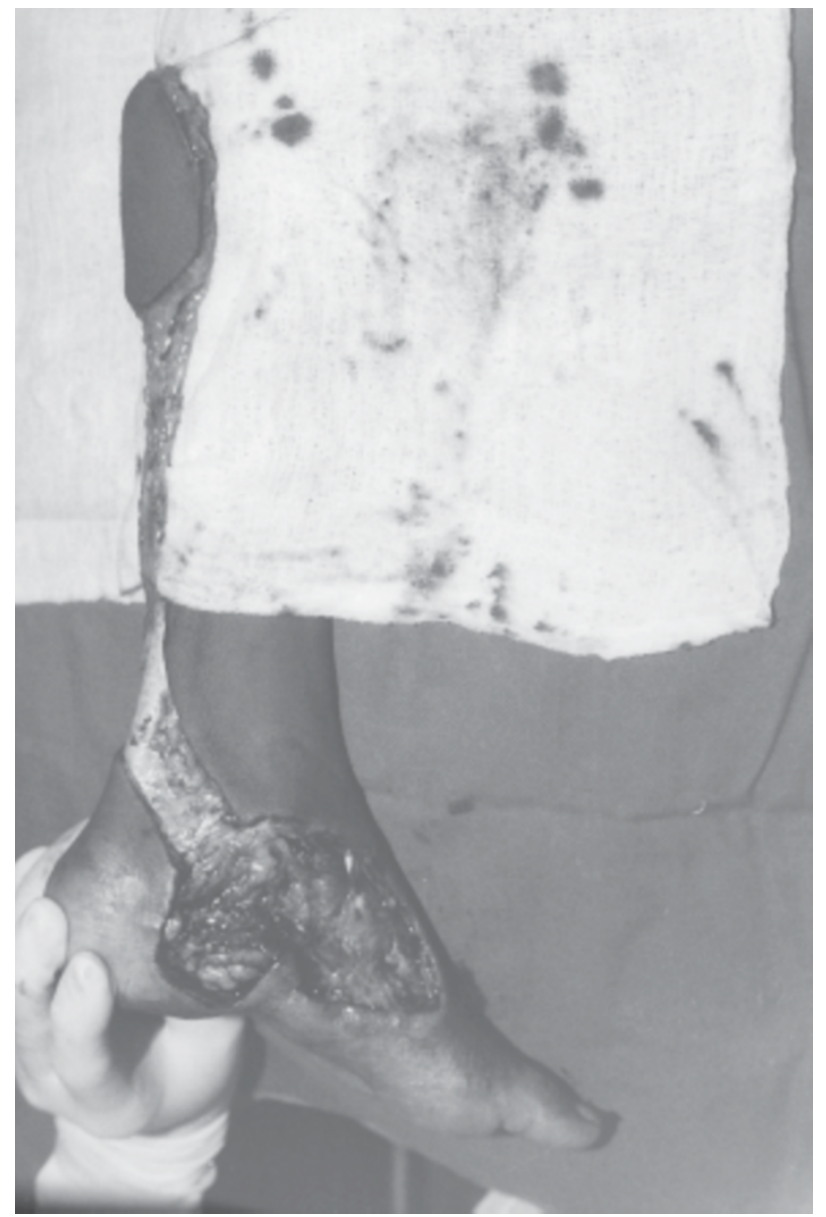

Fig. 1 : Posttraumatic soft tissue defect left foot after wound debridement. Distally based sural artery flap has been raised not suitable because of trauma, scarring or infection. 3 superficial soft tissue defects were resurfaced with split skin grafts. Postoperative wound infections were noted in 3 patients. Two of them were diabetic and one was a case of peripheral vascular disease. They were managed with local and systemic antibiotics according to culture sensitivity reports. Skin grafts applied at flap donor site healed well except partial loss in one patient which required regrafting with stored autograft. One fasciocutaneous flap developed partial necrosis, however the deep fascia was surviving. After wound debridement and dressing the defect was resurfaced with split skin graft. Hyperkeratosis occurred at the margins of 2 instep flaps.

All patients were assessed postoperatively after flap healing had occurred. The assessment included examination of the flap for touch and pressure sensations. Distally based superficial sural artery flap and free flaps which were neurotized took about six to twelve months for protective sensation to develop whereas grafted skin took only six to eight weeks time. However, the quality of sensation was better in the flaps. Ambulation in normal footwear was possible in all of the cases.

\section{Discussion}

Soft tissue defects of the ankle and foot used to be enigma of reconstructive surgeons. Trauma due to road traffic accidents, diabetes mellitus and peripheral

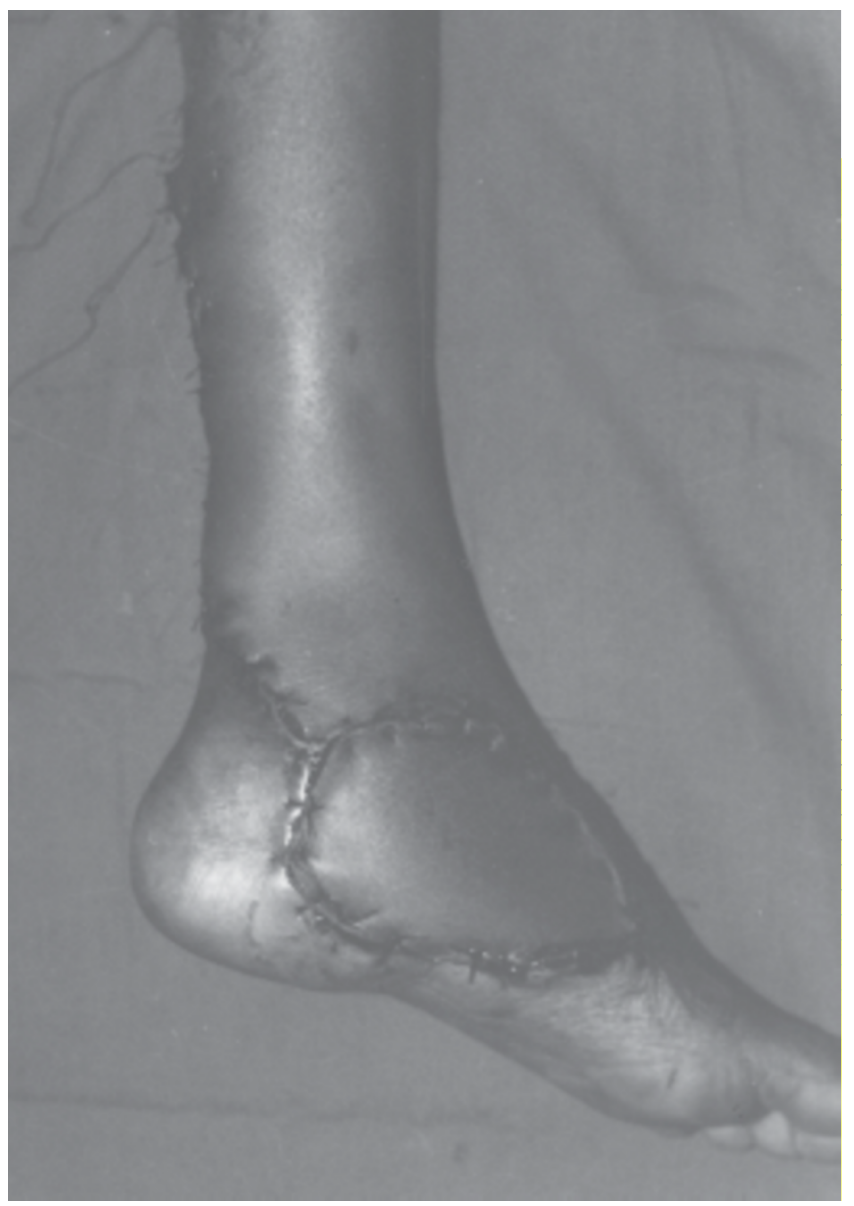

Fig. 2 : Defect has been covered with flap 
vascular disease account for most of the cases presenting with soft tissue losses on ankle and foot. Various techniques have been developed for reconstruction of these defects. Split skin graft remains the best option to cover superficial soft tissue defects on the dorsum of foot on account of faster take and early neurotization. However, occasional graft breakdown continues to be a problem. Fasciocutaneous flaps were introduced by Ponten in 1981 [1] and since then are in use in reconstruction of soft tissue defects of the leg and foot. Inferiorly based muscle flaps have a high failure rate due to their variable vascular anatomy distally. Reversed island flaps such as the peroneal artery flap, anterior tibial artery flap and posterior tibial artery flap can be transferred to the ankle or foot. However, the need to sacrifice a major artery constitutes a potentially serious disadvantage. Skin over the sole, especially the weight bearing portion requires reconstruction by like tissues for long term function. The instep flap raised on the instep region of sole between the heel and metatarsal heads is ideal to reconstruct weight bearing heel defects [2].

In 1992, Masquelet et al first described a distally based flap based on the vascular axis around the sural nerve [3]. This was called distally based superficial sural artery flap. This flap has been shown to be ideal for reconstruction of medium and large soft tissue defects of the ankle and foot. The distally based superficial sural artery flap is vascularised by a median superficial sural artery with reverse flow as this artery takes septocutaneous perforators from peroneal and tibial aerteries in the distal part of leg [4]. Additionally, the sural nerve has an intrinsic arterial system. These systems anastomose freely in the suprafacial plexus; combinations of these systems are used to perfuse the distally based superficial sural artery flap [5]. The major advantage of this flap is the relatively large size that can be harvested with little donor-site deformity. Dissection of the flap is easy and blood loss is minimal. If a thin flap is required the adipofascial flap can be used. If a neurosensorial flap is required, the lateral sural cutaneous nerve can be transferred with the flap and coapted to a recipient nerve in the defect to be reconstructed. This flap has a wide arc of rotation on its pedicle at approximately $5 \mathrm{~cm}$ superior to the lateral malleolus (location of peroneal perforator) and is useful for reconstruction of defects on heel, malleoli, ankle and foot. In our study, this flap was used in 12 patients to cover defects on the anterolateral aspects of ankle weight bearing surface and posterior aspect of heel.

Development of operating microscope has allowed for microvascular anastomosis between vessels of very small diameter ( 1 to $3 \mathrm{~mm}$ ). With this technique composite tissue is detached completely along with its vascular pedicle and anatomosed to recipient vessels at a distant site. Many series of elective free tissue transfers report a success rate higher than 95 percent. In this study, free flaps were done in 3 patients. The main advantages of these flaps are that they are well vascularised and can be neurotized, the disadvantage being that they require necessary equipment, expertise and long operating hours [6]. Distally based superficial sural artery flap remains our choice for reconstruction of soft tissue defects of the ankle and foot because the blood supply is reliable, elevation is easy and quick and the major arteries are not sacrificed.

\section{References}

1. Ponten B. The fasciocutaneous flap. Its use in soft tissue defects of the lower leg. Br J Plast Surg 1981; 34:215-20.

2. Harrison DH and Morgan BDG. The instep island flap to resurface plantar defects. Br J Plast Surg. 1981; 34: 315-8.

3. Masquelet AC, Romanan MC and Wolf G. Skin island flap supplied by the vascular axis of the sensitive superficial nerves. Anatomic study and clinical experience in the leg. Plast Reconstr Surg. 1992; 89:1115-19.

4. Hasegawa M, Torii, Katoh H, and Esaki S. The distally bases superficial sural artery flap. Plast Reconstr Surg. 1994; 93:101220.

5. Yilmaz M, Karatas O, Barutcu A. The distally based superficial sural artery island flap : Clinical experiences and modifications. Plast Reconstr Surg. 1998; 102:2358-67.

6. Serafin D, Georgiade NG and Smith DH. Comparison of free flap with pedicled flaps for coverage of defects of the leg or foot. Plast Reconstr Surg. 1977; 59:492-6. 